\title{
PERCEPÇÓES DOCENTES EM TEMPOS DE (RE) APRENDIZAGENS DOS SABERES DE LINGUAGEM: UM ESTUDO DA ORGANIZAÇÃO CURRICULAR EM EDUCAÇÃO PROFISSIONAL E TECNOLÓGICA
}

\author{
Gleyde Ohana Ribeiro dos Santos ${ }^{1}$ \\ Rivadavia Porto Cavalcante ${ }^{2}$ \\ Weimar Silva Castilho ${ }^{3}$ \\ Mary Lúcia Gomes Silveira de Senna ${ }^{4}$
}

\begin{abstract}
Resumo: O objetivo deste artigo é discutir a organização curricular do Curso Técnico em Agropecuária Concomitante à etapa do Ensino Médio, de um Campus Avançado do Instituto Federal de Educação, Ciência e Tecnologia do Tocantins -IFTO. O atual período de pandemia ocasionado pela COVID-19 e o consequente isolamento social requer redefinição dos modos de ensinar-aprender os saberes de linguagem em contextos escolares remotamente. A readequação do ensino à assimilação daqueles saberes pelos alunos carece de ser investigada. O estudo fundamentou-se na teoria sociocultural vygotskyana do desenvolvimento cognitivo humano associada à Teoria de Transposição Didática de Yves Chevallard e da Pedagogia dos letramentos visando fundamentar possíveis reestruturaçóes do saber em contextos de ensino-aprendizagem presencial e virtual. A pesquisa de revisão teórica,
\end{abstract}

1 Mestranda do Programa de Pós-graduação Stricto Sensu em Educação Profissional e Tecnológica - ProfEPT, Campus Palmas do Instituto Federal de Educação, Ciência e Tecnologia do Tocantins (IFTO). Licenciada em Pedagogia pela Universidade Federal do Tocantins (UFT) e atua como Pedagoga/orientadora educacional (IFTO). E-mail: gleyde.santos@ifto.edu.br

2 Doutor em Linguística pela Universidade Federal da Paraíba (UFPB). Estágio de Doutorado Sanduiche (PDSE/CAPES) -Boursier d'excelence - pela Universidade de Genebra (UNIGE), Suíça. Professor pesquisador do Instituto Federal de Educação, Ciência e Tecnologia do Tocantins (IFTO) e do Programa de Mestrado em Educação Profissional e Tecnológica em Rede Nacional - ProfEPT, Campus Palmas -IFTO. E-mail: riva@ifto.edu.br

3 Doutor em Sistemas Mecatrônicos pela Universidade de Brasília, professor pesquisador do Instituto Federal de Educação Ciências e Tecnologia do Tocantins - IFTO, Campus Palmas. Professor do curso de Licenciatura em Física e do Mestrado Profissional em Educação Profissional e Tecnológica em Rede Nacional - ProfEPT. E-mail: weimar@ifto.edu.br

4 Doutora em Ciências pela Universidade de São Paulo (USP). Professora pesquisadora do Instituto Federal de Educaçáo, Ciência e Tecnologia do Tocantins - IFTO - e do Programa de Mestrado em Educação Profissional e Tecnológica em Rede Nacional - ProfEPT, Campus Palmas, IFTO. E-mail: marysenna@ifto.edu.br 
análise documental e estudo de caso possibilitaram estudar qualitativamente o ementário da disciplina "Redação de Documentos Técnicos e Oratória" do referido curso. Mediante entrevista semiestruturada com o professor da disciplina, constatamos limitaçôes na transposição didática dos saberes a ensinar no contexto de ensino presencial e remoto. Os resultados indicam a urgência de revisão na organização curricular e atualização dos métodos de ensino da linguagem devido à recente reconfiguração dos modos de ensinar e aprendê-la associada às novas tecnologias.

Palavras-chave: Linguagens e Letramento. Organização curricular. Formação Profissional.

\title{
TEACHING PERCEPTIONS AT A TIME OF (RE)LEARNING OF THE KNOWLEDGE OF LANGUAGE: A CURRICULUM ORGANIZATION STUDY IN PROFESSIONAL AND TECHNOLOGICAL EDUCATION
}

\begin{abstract}
The purpose of this article is to discuss the curricular organization of the Technical Course in Agricultural Concomitant with the High School stage, of an Advanced Campus of Federal Institute of Education, Science and Technology of Tocantins -IFTO. The current pandemic period caused by COVID-19 and the consequent social isolation requires redefining the ways of teaching-learning language knowledge in school contexts remotely. The readjustment of teaching to the assimilation of that knowledge by students needs to be investigated. The study was based on the Vygotskyan sociocultural theory of human cognitive development associated with the Didactic Transposition Theory of Yves Chevallard and Pedagogy of Literacies aiming to support possible restructuring of knowledge in classroom and virtual learning contexts. Theoretical review research, document analysis and case study made it possible to qualitatively study the subject of the course "Writing Technical Documents and Public Speaking" for the course. Through a semi-structured interview with the professor of the discipline, we found limitations in the didactic transposition of the knowledge to be taught in the context of face-to-face and remote teaching. The results indicate the urgency of revising the curricular organization and updating the language teaching methods due to the recent reconfiguration of the ways of teaching and learning associated with new technologies.
\end{abstract}

Keyword: Language and Literacy. Curricular organization. Professional training.

\section{INTRODUÇÃO}

Durante esta década o processo de ensino-aprendizagem vem sendo fortemente marcado, de forma especial, pela redefiniçáo dos usos da linguagem devido à urgência dos atos comunicativos, orais ou escritos, entre outras modalidades, com propósitos de veicular conhecimentos e informações sobre as novas condiçóes de vida da sociedade brasileira que vivencia o recolhimento social em tempos de pandemia, com vistas ao período de pós-pandemia a nível mundial.

Diante das incertezas que emergem deste cenário, a revisão dos conceitos de ensino-aprendizagem dos saberes da linguagem, com o intuito de promover práticas de letramentos, no atual contexto de formação profissional, torna-se essencial. Principalmente no que tange à organização dos conhecimentos, de seus conteúdos que podem/precisam ser ensinados, a construção/organização de materiais didáticos 
e de espaços de ensino-aprendizagem que se adequem às demandas de professores e alunos.

Perante esse cenário complexo, as teorias de aprendizagem podem auxiliar significativamente o processo de ensino-aprendizagem, tanto de estudantes como de educadores. Além do mais, as transformaçōes sociais ocorridas ao longo dos tempos têm demandado estratégias educativas cada vez mais diversificadas e que sirvam eficazmente aos diferentes níveis escolares de ensino, desde os anos iniciais até o saber ensinado para além das Universidades.

Porém, em face dos desafios nos dias atuais, faz-se premente pensar e refletir sobre as aprendizagens, náo apenas dos hábitos cotidianos, mas sobretudo sobre a construção de novos saberes para a vida e para as profissóes. Considerando que a linguagem é constitutiva da existência humana, das atividades e práticas sociais (VYGOTSKY, 2001; BAKHTIN, 2011, 2014), sua ênfase no currículo e nas salas de aula torna-se substancial para avançarmos nessa direção.

Partindo desses pressupostos, o objetivo central deste artigo é refletir e discutir teoricamente sobre a organizaçáo curricular do Curso Técnico em Agropecuária Concomitante à etapa do Ensino Médio, de um Campus Avançado do Instituto Federal de Educaçáo, Ciência e Tecnologia do Tocantins - IFTO, com vistas à atualização do componente Redação de Documentos Técnicos e Oratória, já que vivenciamos tempos de mudanças sociopolíticas e culturais que requerem (re) aprendizagens dos modos de ensinar e aprender, inclusive de forma náo presencial.

Dessa forma, a realização de estudos que evidenciem as expectativas, inquietações e limitações de professores e alunos, quanto à implementação do programa escolar de disciplinas é de primordial importância, especialmente, diante de nossa atual conjuntura.

Para tanto, assume-se como objetivo específico, investigar nos relatos do professor suas percepçóes sobre o processo de ensino-aprendizagem dos saberes de linguagem contidos na ementa da disciplina durante este período de pandemia e isolamento social.

Ademais, em tempos de isolamento social devido ao alto nível de transmissão comunitária decorrente do novo Coronavírus, a COVID-195, também, tempos de reformas sociais, envolvendo educação, currículo e o saber, conforme dispóe a Lei 13.415/17 e a Base Nacional Comum Curricular - BNCC, por exemplo, fazse premente a revisão dos elementos constituintes da organização curricular dos cursos, também, nos contextos de Educação Profissional e Tecnológica - EPT.

5 Este termo se refere a uma doença causada pelo novo coronavírus, este último se caracteriza por uma família de vírus que causam infecçōes respiratórias. A doença apresenta um quadro clínico que varia de infecçôes assintomáticas a quadros respiratórios graves. De acordo com a Organização Mundial de Saúde (OMS) a maioria dos pacientes com COVID-19 (cerca de 80\%) podem ser assintomáticos e cerca de $20 \%$ dos casos podem requerer atendimento hospitalar por apresentarem dificuldade respiratória e desses casos aproximadamente $5 \%$ podem necessitar de suporte para o tratamento de insuficiência respiratória. 
Dessa forma, esta atitude se inscreve, como ação didático-pedagógica centrada na prática dos letramentos (ROJO, 2013), com propósitos de garantir a efetivação dos conhecimentos linguageiros a serem ensinados, de forma significativa, diante dos desafios e da imprevisibilidade de implementação das recentes políticas educacionais de uma sociedade que está em constante mudanças.

\section{LINGUAGEM, ENSINO-APRENDIZAGEM E A CONTRIBUIÇÃO VYGOTSKYANA}

Evidenciamos que as relaçóes humanas, atualmente, estão, sobremaneira, mediadas pelo uso das novas tecnologias, de tal modo que as barreiras geográficas não se constituem mais como um empecilho para que a informação e a comunicação cheguem até nós. Dessa maneira, a teoria do desenvolvimento cognitivo ou sociocultural de Vygotsky $(1991,2001)$ nos esclarece que os contextos em que as relaçóes sociais e culturais acontecem, além dos vínculos que realizamos uns com os outros, são determinantes para as construçóes psicológicas que vamos estabelecendo mentalmente ao longo de nossas vidas.

Condizentes com Moreira (1999), a respeito da teoria vygotskyana, todo progresso mental superior se desenvolve primeiro por meio de influências externas do contexto histórico, cultural e social em que o sujeito se localiza, isto é, um processo evolutivo, em que, inicialmente, a aprendizagem é concebida interpsiquicamente e, só depois, é internalizada. Uma das características pelas quais a teoria trazida por Vygotsky (2001) se destaca é por ter buscado compreender o desenvolvimento cognitivo humano em seu viés macro, a partir das relaçóes que o ser opera com a cultura vivenciada e com o grupo social em que se encontra inserido. Desse modo, estudiosos de Vygotsky (DRISCOLL, 1995; MOREIRA, 1999) elucidam que, para o autor russo, o desenvolvimento mental superior possui natureza social, mediante as interaçóes entre os sujeitos, de modo que, níveis cada vez maiores de cognição são construídos durante os momentos de socialização e que se converterão em progressivas capacidades mentais: pensamento, linguagem e comportamento volitivo.

Temos, então, em Vygotsky (2001), alguns conceitos primordiais para a compreensão do desenvolvimento das funçôes psicológicas do ser, como por exemplo, o de "Mediação" que ocorre dentro de contextos sócio-históricos e culturais num movimento de dialogicidade entre os envolvidos, bem como o conceito de "Internalização" do saber e do conhecimento adquiridos.

Em consequência disso, o ser deve ser compreendido de forma heterogênea, tendo em vista os mais diversos contextos e realidades sociais existentes, partindose do princípio de que o sujeito não nasce pronto ou acabado, assim como o conhecimento também é construído e reconfigurado ao longo dos tempos. Chevallard (2013) destaca que o conhecimento, mais especificamente, aquele que é desenvolvido em contextos escolares, diferente dos demais conhecimentos propagados nas outras relaçôes sociais, é carregado de intencionalidade didática, ou seja, da intenção de ensinar. 
Com ênfase no desenvolvimento do processo de ensino-aprendizagem, Vygotsky (1991, p. 33), evidencia o conceito de "Internalização" do conhecimento absorvido nas interaçóes com o meio, com as coisas do mundo e as pessoas. Essa relação de "internalização" não se resume em introduzir automaticamente os saberes e costumes advindos das interaçóes sociais, mas da capacidade de transformá-los para si. Já o conceito de "Mediação" propicia um movimento de trabalho mais significativo para estudantes e professores. Nessa dinâmica, a mediação inicia-se com a atuação do professor, mas não se encerra nele, pois os instrumentos e ferramentas, as demais situaçóes e interaçóes propostas serão consideradas como medidas eficazes para o processo de ensino-aprendizagem.

Outra contribuição vygotskyana, bastante pertinente para este estudo, é o conceito de Zona de Desenvolvimento Proximal - ZDP, ou Zona de Desenvolvimento Iminente, como também é conhecido em algumas traduçóes. Partindo dos seus estudos realizados com crianças, Vygotsky identifica dois níveis de desenvolvimento. O primeiro, parte do grau de conhecimento que uma criança conseguiu atingir, isto é, tudo aquilo que ela consegue realizar sozinha e de forma independente, a este nível Vygotsky denomina de Desenvolvimento Real; e, o segundo, de Desenvolvimento Potencial, onde se considera tudo o que uma criança consegue realizar com o auxílio de outra pessoa mais experiente do que ela.

É neste ínterim, entre aquilo que o sujeito, seja uma criança ou adulto, consegue realizar sozinho, até aquilo que ele pode aprender por intermédio da sua interação com os outros é que Vygotsky descreve como Zona de Desenvolvimento Proximal ou Iminente. Ou seja,

[...] esse "fazer em colaboraçáo" náo anula mas destaca a participação criadora da criança e serve para medir o seu nível de desenvolvimento intelectual, sua capacidade de discernimento, de tomar a iniciativa, de começar a fazer sozinha o que antes só fazia acompanhada, sendo, ainda, um valiosíssimo critério de verificação da eficácia do processo de ensino-aprendizagem (VYGOTSKY, 2001, p. X, prefácio).

Podemos dizer, então, que é neste espaço de tempo que o professor e/ou educador poderá intervir e contribuir. Por isso é essencial entender que "a conversão de relaçôes sociais em funções mentais superiores não é direta, é mediada. E essa mediação inclui o uso de instrumentos e signos" (MOREIRA, 1999, p. 110). Para Vygotsky (2001, p. 11-12), o termo "signo" equivale à palavra "sentido", e se torna um elemento essencial às interaçóes discursivas entre os sujeitos. Em tese, três categorias de signos dão sentidos aos ingredientes do ambiente humano, quais sejam: os indicadores de causa e efeito (onde há fumaça há fogo), os icônicos que são representaçóes imagéticas ou gráficas e os símbolos que dão sentidos aos elementos abstratos. "As palavras, por exemplo, são signos linguísticos, os números são signos matemáticos; a linguagem falada e escrita, e a matemática são sistemas de signos" (MOREIRA, 1999, p. 111).

A teoria de Vygotsky se constitui, então, como uma forma de ver e agir sobre o fenômeno da aprendizagem e, a partir dela, o professor poderá arquitetar situaçóes, 
propor mecanismos e selecionar métodos para melhor mediar a construção do conhecimento em sala de aula, por exemplo.

\section{CONTRIBUIÇÓES DA TRANSPOSIÇÃO DIDÁTICA PARA O ENSINO- APRENDIZAGEM DOS SABERES DE LINGUAGENS}

A respeito das relaçóes desencadeadas durante o processo de ensinoaprendizagem, fundamentalmente, sobre as práticas que são desenvolvidas em sala de aula, temos, então, o que Chevallard (1991) intitula como "Transposição Didática". Os estudos de Chevallard (1991, 2013) nos revelam que o saber cientificamente produzido, isto é, o saber de referência, pode e deve sofrer uma série de adaptaçôes para que se torne, de fato, um objeto de ensino. Este trabalho desprendido ao conhecimento, por meio de um conjunto de transformaçóes adaptativas, para que o saber se torne um objeto ensinável, é conhecido como processo de Transposição Didática.

Considerando isto, a proeminência da teoria de Vygotsky em diálogo com os estudos desenvolvidos por Yves Chevallard, percebemos que, para a teoria assumir seu verdadeiro protagonismo em situaçóes práticas do cotidiano escolar, faz-se mais do que necessário transpor o saber antes legitimado nas Instituiçóes de pesquisa el ou nas Universidades para um saber que objetive o aprender do aluno através da prática efetivamente ensinável pelo professor.

Para uma melhor compreensão, realçamos o olhar trazido por Chevallard de que "a relação didática une três e não dois 'objetos' a saber: o professor, o ensino e, por último, mas náo menos importante, o conhecimento; ou, para ser ainda mais preciso, o conhecimento ensinado" (CHEVALLARD, 2013, p. 6), estes são três aspectos mínimos, a serem considerados pelo autor, o que coaduna com a proposta levantada por Vygotsky em sua teoria histórico-cultural, pois, nas relações didáticas de ensino-aprendizagem a seleção do conhecimento e a forma de lidar com este, claramente influenciará as relaçóes entre professor, estudante, pais, gestores, etc., e, principalmente, porque essa relação constitui-se fator decisivo para a consecução dos resultados.

Com relação a essa abordagem e sua influência no processo de aquisição do conhecimento, Vygotsky aponta para a importância de se considerar as experiências socioculturais desses sujeitos por meio de instrumentos adequados para tal. Ademais, "o desenvolvimento do pensamento e da linguagem depende dos instrumentos de pensamento e da experiência sociocultural [...]" (VYGOTSKY, 2000, p. 149). Assim posto, o reconhecimento dessas mesmas experiências, anteriormente vivenciadas pelos alunos no processo ensino-aprendizagem, se torna relevante e eficaz para uma transposição didática mais coerente dos saberes de linguagem na implementação da organização curricular.

Com base na teoria vygotskyana, compreendemos que a linguagem humana é desenvolvida e aprimorada na e pela interação dos sujeitos com o meio social. Esta vivencia possibilita, portanto, a aquisição e o aprimoramento da linguagem, 
iniciando-se a partir dos saberes advindos do contexto sociocultural de origem em direção a níveis mais elaborados e diversos de linguagem. Assim, o autor assegura que,

[...] o pensamento verbal não é uma forma natural e inata de comportamento mas uma forma histórico-social, e por isso se distingue basicamente por uma série de propriedades e leis específicas, que não podem ser descobertas nas formas naturais do pensamento e da linguagem (VYGOTSKY, 2000, p. 149).

Essas assertivas suscitam refletir que a concepção que se tem da língua e da linguagem pode influenciar de modo positivo ou negativo o trabalho de transposiçáo didática do professor. Sobre isso, os aportes de Bakhtin (2011) trazem contribuições bastante pertinentes para uma compreensão mais acurada e concreta da língua/gem, enquanto prática social, auxiliando na superação dos princípios estruturalistas ainda vigentes na organização curricular dos saberes linguageiros. Para o estudioso citado, a língua se define e se concretiza nas práticas dialógicas e não por meio de suas formas estruturais e de normas gramaticais. Dito em outros termos, tais práticas da língua se realizam e se materializam nos diálogos estabelecidos pelos interlocutores no instante mesmo de suas interaçôes comunicativas.

Em vista disso, não se pode ignorar a compreensão do funcionamento da língua nas açôes de transposição didática em contextos escolarizados, posto que tais espaços de aprendizagem requerem dos educadores o entendimento da diversidade cultural e linguística trazida por seus alunos. Logo, torna-se consideravelmente necessário que professores levem em conta a natureza dos enunciados, as especificidades do gênero, que determinam a pluralidade discursiva e seus modos de produção, circulação e recepção nas diversas esferas da sociedade, objetivando a superaçáo do ensino formalista centrado na abstraçáo dos conteúdos, de maneira a privilegiar a associação da língua com a vida. As asserçôes postas aqui encontram respaldo nas palavras de Bakhtin ao afirmar que,

A língua materna - a composição de seu léxico e sua estrutura gramatical -, não a aprendemos nos dicionários e nas gramáticas, nós a adquirimos mediante enunciados concretos que ouvimos e reproduzimos durante a comunicação verbal viva que se efetua com os indivíduos que nos rodeiam (BAKHTIN, 2011, p. 301-302).

Assim, conforme o fragmento supracitado, a aprendizagem da língua não se prende ao estudo das estruturas puramente linguístico-gramaticais, nem mesmo ao léxico isolado de seus reais contextos comunicativos. Enunciado e língua são dimensôes da vida humana e das práticas sociais. Assim a apropriação dos saberes de linguagem se dá nas e pelas práticas efetivas das organizaçôes enunciativas em situaçôes especificas das açôes humanas. $\mathrm{O}$ produto dessas relaçōes se materializa no formato escrito ou oral do gênero mobilizado de acordo com os parâmetros contextuais e os propósitos da interação linguageira.

Entendemos, assim, que "Linguagem e realidade se prendem dinamicamente" (FREIRE, 1989, p. 11.), dado que, se esse movimento de dialogicidade não é possibilitado ao mundo do aluno, o saber torna-se algo desprovido de sentido, em 
sua forma mais concreta, para esse aprendente. Esta realidade, Paulo Freire (1989) a retrata como "leitura de mundo", no sentido de dar a devida importância aos estímulos trazidos pela linguagem que é estabelecida em contextos mais pessoais de vivência dos sujeitos, como nos convívios de cultura local, por exemplo. Um dos legados de Freire para a educação foi enxergá-la como um ato político e criador, na medida em que todo ato educativo se insere como uma intervençáo transpassada de significância e intencionalidade. Freire considera que "a leitura de mundo antecede a leitura da palavra", sendo esta prática social de suma importância ao planejamento e execução escolar de modo que "a compreensão do texto a ser alcançada por sua leitura crítica implica a percepção das relações entre o texto e o contexto" (FREIRE, 1989).

Nessa perspectiva, as práticas sociais dos usos da fala e da escrita são características basilares do conceito de Letramentos ${ }^{6}$. Estudiosos da linguagem contemporânea (GAGLIARDI, 2012; ROJO, 2013. GARCIA ET AL, 2016) evidenciam que tal noção precisa estar associada à apropriação e às práticas dos saberes das múltiplas linguagens contemporâneas associadas às tecnologias digitais de informação e comunicação - TDIC, entre outras formas de conhecimentos sóciohistoricamente construídos implicando nos mais distintos atos comunicativos.

Embora tais tecnologias estejam presentes na vida cotidiana do público estudantil, ainda, demonstram-se ausentes nas salas de aula, o que constitui na contradição da educação brasileira suscitando foco de preocupação dos professores na construção e execução dos currículos escolares que, nem sempre, dialogam com a realidade social e suas demandas.

Com isso, o ensino de Língua Portuguesa, em contextos escolares, tornase cada vez mais um caminho desafiador a ser trilhado por professores (as) e suas Instituições de Ensino, já que são demandadas novas formas e instrumentos de ensino para a efetivação da aprendizagem significativa dos estudantes. Dessa forma, faz-se necessário buscar elementos teóricos e didático-pedagógicos para a construção de instrumentos de ensino que se adequem às particularidades dos contextos escolares centrados em uma pedagogia de práticas de letramentos.

Observemos, pois, que os processos de interação social, em nossa atualidade, não se restringem totalmente ao contato físico e presencial, mas, dinamicamente, se dáo por meio da (multi)plicidade de linguagens já disseminadas em nosso meio. A respeito disso, temos que

[...] atualmente, o texto escrito também não é mais o principal em alguns gêneros. Existem muitos formatos para comunicar que consideram a relaçáo da imagem com a escrita ou da imagem com o movimento. Essas novas

6 A expressão "letramento" entrou na língua portuguesa em meados dos anos 1980 e hoje tornouse bastante comum, mas nem sempre de forma clara. Para uma melhor análise desse aspecto, podem-se ver as ponderaçóes de Magda Soares $(1998,2003)$. Em termos gerais, o letramento diz respeito às práticas discursivas que fazem uso da escrita. Uma pessoa pode ser letrada sem ter ido à escola, pois ela tem um letramento espontâneo. (MARCUSCHI, 2007, p.32). 
configuraçóes motivaram a ideia de multiletramentos, que abrange os letramentos da letra e também os letramentos da imagem e do som (ROJO, 2013, p. 08).

As capacidades cognitivas e competências dos estudantes estão cada vez mais atreladas ao uso das TICs. E-book, vídeos, podcast, games educativos, blog; inclusive, táo logo agora, em tempos emergenciais de trabalho remoto, o uso de ferramentas para videoconferências, atividades online, entre outras, são exigências de uma sociedade dita pós-moderna, e a escola se inclui nessa esfera. Considerar essa realidade é estar em sintonia com as transformaçóes ocorridas no/e para além do mundo dos estudantes.

Decorrente disso, urge considerar que a organização curricular e os saberes a serem ensinados e aprendidos devem passar por contínuas redefiniçóes pautadas por um posicionamento crítico-reflexivo na busca incessante de conferir sentido à dinâmica entre escola e vida (GRAMSCI, 2009). A este respeito, Rojo (2013) chama-nos à atenção para a relevância de se compreender as multilinguagens, os novos modos e estilos de aprendizagens dos alunos dos dias atuais, ainda não contemplados como objetos de ensino em muitas escolas. Segundo a estudiosa dos letramentos, "os gêneros que estão na internet misturam culturas o tempo todo".

Dessa forma, a sala de aula comporta alunos com valores culturais diversificados, em termos de suas preferências de leitura e linguagens. Embora nem todas as escolas incorporem tal diversidade em seus currículos, tais instituiçóes deveriam entrar em diálogo para poder, justamente, colocar o aluno em diálogo com o repertório do patrimônio (ROJO, 2013, p. 9).

O desafio das escolas se constitui, entáo, em aproximar os saberes vivenciados pela leitura de mundo, inclusive das novas tecnologias trazidas pelos estudantes, aos saberes basilares e clássicos, já presentes nos currículos escolares, que, a este último, Vygotsky (2001), denomina de "conceitos científicos" e, ao primeiro, de "conceitos espontâneos". O fato é que, em inúmeras vezes, o computador já se encontra inserido na escola, ocasião que náo se constitui suficiente para que o aluno desenvolva suas capacidades de oralidade e escrita de forma crítica e reflexiva, "isso é muito diferente de produzir um vídeo ou um áudio, de manejar ferramentas de curadoria, de vivenciar redes sociais com finalidade pedagógica" (ROJO, 2013, p. 10). A intervenção do professor é a de mediar as situaçóes de aprendizagem e buscar relacionar escola/vida, sem desconsiderar a proeminência do uso das novas TICs durante o desenvolvimento das atividades de ensino. A autora orienta o uso equilibrado dos materiais didáticos digitais junto ao uso dos materiais impressos, com vistas à implementação tanto do letramento tradicional como dos multiletramentos. 


\section{ÁREA DO CONHECIMENTO LINGUAGEM E SUAS TECNOLOGIAS: O COMPONENTE CURRICULAR DE LÍNGUA PORTUGUESA}

Trazemos para esse estudo um dos documentos mais importantes em torno de debates no que diz respeito à Educação no país, na atualidade, a Base Nacional Comum Curricular ou BNCC, como é popularmente conhecida. A BNCC é um documento ratificado pelo Ministério da Educação (MEC) que sofreu três etapas de elaboração para chegar até a sua atual conjuntura. Em dezembro de 2017 foram homologados os documentos relativos às etapas do Ensino Fundamental e da Educação Infantil. Já em dezembro de 2018, um novo documento foi criado para a etapa de Ensino Médio. Assim, hoje, nos é apresentado um único documento, contendo toda a Base Nacional, que traz em seu bojo uma proposta de adequação curricular para todos os três níveis escolares, tanto de escolas públicas como privadas do país.

Para Sacristán (2000), os currículos se apresentam como uma espécie de estabilidade entre as forças que giram em torno do sistema educativo em um dado momento da história. Por isso, compreendemos que o currículo é um campo de crescentes disputas e interesses em que se objetivam os rumos a serem traçados no ensino escolarizado.

Logo, segundo a BNCC, há uma base de conhecimentos que deverão ser preconizados nas construçóes dos currículos de cada Instituição de Ensino pública e privada do Brasil, isto é, uma base de conhecimentos que norteie todo o processo de ensino-aprendizagem desenvolvidos nestas Instituiçóes. Ou seja, o caráter centralizador encontrado na Base é definido por um ensino mínimo a que todos tenham direito.

A BNCC, em sua formulação direcionada à etapa do Ensino Médio, claramente se refere ao público estudantil deste ciclo escolar, majoritariamente composto por adolescentes e jovens, como estudantes que vivenciam suas "juventudes". Com referência ao termo "Juventudes" e não "Juventude", o documento adverte que,

Adotar essa noção ampliada e plural de juventudes significa, portanto,
entender as culturas juvenis em sua singularidade. Significa não apenas
compreendê-las como diversas e dinâmicas, como também reconhecer os
jovens como participantes ativos das sociedades nas quais estáo inseridos,
sociedades essas também tão dinâmicas e diversas (BRASIL, 2018, p. 463,
grifo nosso).

Partindo dessas constataçôes, verificamos, então, que a atual BNCC fundamenta suas proposições alicerçadas nos conceitos de heterogeneidade em apreço à condiçáa sócio-histórico-cultural dos sujeitos desta etapa de ensino. Ademais, identificamos também os anseios de formação previstos para esse público, tais como a autonomia, a criticidade e a criatividade, bem como o devido uso de condutas responsáveis; embora, ainda, percebamos que o quesito balizador contido na BNCC esteja centrado no papel de educaçáo e escola fortemente associado à ideia de objetivar uma educaçáo de caráter utilitário, pragmático e com um excessivo direcionamento para as exigências da sociedade moderna. 
Desse modo, consideramos o real papel que a BNCC representa em âmbito educacional que é o de fundamentar a construção dos currículos que serão desenvolvidos exclusivamente pelas Instituiçôes de Ensino Escolar. Neste sentido, esse documento de cunho normativo propóe que as três etapas da Educação Básica propiciem o desenvolvimento progressivo de atividades essenciais para a aquisiçáo de competências durante o período de vivência estudantil dos alunos. E como vemos a seguir,

[...] ao longo da Educação Básica, as aprendizagens essenciais definidas na BNCC devem concorrer para assegurar aos estudantes o desenvolvimento de dez competências gerais, que consubstanciam, no âmbito pedagógico, os direitos de aprendizagem e desenvolvimento. Na BNCC, competência é definida como a mobilização de conhecimentos (conceitos e procedimentos), habilidades (práticas, cognitivas e socioemocionais), atitudes e valores para resolver demandas complexas da vida cotidiana, do pleno exercício da cidadania e do mundo do trabalho (BRASIL, 2018, p. 8, grifos nossos).

Logo, o foco deste estudo se centra em analisar como estas competências e habilidades podem ser desenvolvidas em contextos de sala de aula do Ensino Médio, por isso nos propomos a conhecer como uma das áreas do conhecimento está evidenciada no documento da BNCC, a saber a "Área de linguagem e suas tecnologias" e as orientações dadas ao componente curricular de Língua Portuguesa. Vejamos que:

No Ensino Médio, o foco da área de Linguagens e suas Tecnologias está na ampliação da autonomia, do protagonismo e da autoria nas práticas de diferentes linguagens; na identificação e na crítica aos diferentes usos das linguagens, explicitando seu poder no estabelecimento de relações; na apreciação e na participação em diversas manifestaçôes artísticas e culturais; e no uso criativo das diversas mídias (BRASIL, 2018, p. 471, grifos nossos).

Por isso, consideramos que as formas de linguagem estão atreladas à comunicaçáo, e esta comunicação por meio da linguagem faz parte da esfera interacional dos sujeitos, Vygotsky (2001). No entanto, é sabido que as práticas comunicativas mediante os processos de interaçáo humana podem acontecer de diversas formas, não se restringindo apenas às práticas orais e escritas, já bastante disseminadas em contextos escolares. Isto porque, conforme as teorizações de Bakhtin $(2011,2014)$, a linguagem (e/ou a língua) é caracterizada pela diversidade cultural na multiplicidade de sentidos que adquire em cada âmbito de atividade social.

Como a própria BNCC nos revela, temos um leque de artifícios para nos comunicarmos, como por exemplo, as linguagens corporais, as de sinais, as artísticas, dentre muitas outras maneiras para que a comunicação se concretize. Além de que, a construção curricular proposta na atual Lei de Diretrizes e Bases da Educação $\mathrm{LDB}$, preconiza que

$\$ 8^{\circ}$ Os conteúdos, as metodologias e as formas de avaliação processual e formativa seráo organizados nas redes de ensino por meio de atividades 
teóricas e práticas, provas orais e escritas, seminários, projetos e atividades online, de tal forma que ao final do ensino médio o educando demonstre:

I - Domínio dos princípios científicos e tecnológicos que presidem a produção moderna; (

II - Conhecimento das formas contemporâneas de linguagem (BRASIL, 1996, art. 35, grifos nossos).

É importante destacar que, sim, todas as outras práticas comunicativas da linguagem se reportam e/ou partem do texto escrito, mas que seu fim não se limite a ele, quando o assunto é o ensino da Língua Portuguesa e as formas de comunicação desenvolvidas tanto em sala de aula como fora dela.

\section{POLÍTICA CURRICULAR PARA A EDUCAÇÃO PROFISSIONAL TÉCNICA DE NÍVEL MÉDIO}

A Constituição brasileira prevê que a educação se efetive como um "[...] direito de todos e dever do Estado e da família [...] visando ao pleno desenvolvimento da pessoa, seu preparo para o exercício da cidadania e sua qualificação para o trabalho" (BRASIL, 1988, art. 205). O que pressupóe um modelo de Educação que propicie às pessoas uma formação plena, que tem por sinônimo a oferta do saber integral, sem deixar de considerar, inclusive, a preparaçáo para o trabalho.

Todavia, as premissas legais destinadas à construção do currículo do ensino médio profissionalizante não têm sido suficientes para superar sua indefinição. Segundo Antônio e Brasil (2013, p 13), a organização do currículo para a educaçáo profissional sofre efeitos da "crise de identidade legal". Decorrente desta, emerge a "crise de identidade pedagógica" afetando o conceito de currículo neste domínio. Tais asserçóes se sustentam tendo em vista os vagarosos progressos ao assunto do ensino médio profissionalizante em detrimento ao que já se produziu ao longo da história.

A seção IV-A da LDB (1996), que trata da Educação Profissional de Nível Médio, dispóe sobre a oferta desta modalidade de ensino optativa aos currículos Institucionais, na qual o ensino médio "poderá" habilitar o estudante para o trabalho técnico, (incluído pela Lei 11.741/2008), tal como vemos:

Art. 36-A. Sem prejuízo do disposto na Seção IV deste Capítulo, o ensino médio, atendida a formação geral do educando, poderá prepará-lo para o exercício de profissóes técnicas.

Parágrafo único. A preparação geral para o trabalho e, facultativamente, as habilitaçóes profissionais poderão ser desenvolvidas nos próprios estabelecimentos de ensino médio ou em cooperação com instituições especializadas em educação profissional (BRASIL, 1996, art. 36-A, grifos nossos).

Como vimos, a Lei 13.415/2017, conhecida como Lei de Reforma do Ensino Médio, alterou alguns pontos essenciais da atual LDB e, de certa forma, problematiza a construçáo curricular desta etapa de ensino no Brasil, ao ampliar a carga horária de forma progressiva "no ensino médio, para mil e quatrocentas 
horas, devendo os sistemas de ensino oferecer, no prazo máximo de cinco anos, pelo menos mil horas anuais de carga horária, a partir de 2 de março de 2017" (BRASIL, 1996 , art. $24, \$ 1^{\circ}$ ), evidente que, fica a cargo da BNCC a organizaçáo curricular a orientar os sistemas de ensino, público e privado do país, de modo a definir,

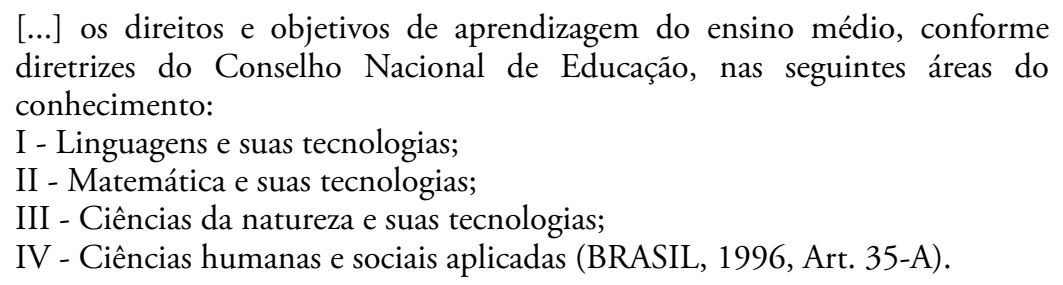

Do exposto, a construção do currículo para o ensino médio será motivada pela BNCC e por itinerários formativos "que deverão ser organizados por meio da oferta de diferentes arranjos curriculares, conforme a relevância para o contexto local e a possibilidade dos sistemas de ensino, a saber: [...] V - formação técnica e profissional" (BRASIL, 1996, art. 36), dentre outros.

Com isso, notamos que a separaçáo da oferta, como um itinerário formativo elevada a uma característica opcional no currículo, põe a formação profissional de nível médio no mesmo nível de inferiorização que ela já vinha assumindo historicamente.

Essa construção curricular corrobora para o que estudiosos da educação (MOURA; FILHO; SILVA, 2015; CIAVATTA; RAMOS, 2011) chamam de dualidade estrutural e histórica e consequente fragmentaçáo do currículo, especialmente imposta pelo sistema capitalista de produção, em que consiste em separar o trabalho manual da formação intelectual. O primeiro, relacionado ao ensino puramente profissionalizante e o último, ao ensino propedêutico, constatações essas que se distanciam de uma concepção plena e/ou integral de educação, como prevê a base legal brasileira em seus dispositivos legais.

Nesta direção, Ciavatta (2008), parafraseando Gramsci (1981), orienta que o trabalho precisa ser entendido como princípio educativo buscando superar o velho paradigma entre trabalho manual versus trabalho intelectual e proporcionar à classe trabalhadora uma formação consciente para sua atuação em sociedade. Como já assinalava Gramsci (2001, p. 52-53), "não há atividade humana da qual se possa excluir toda intervençáo intelectual, não se pode separar o homo faber do homo sapiens".

\section{O PPC DO CURSO TÉCNICO EM AGROPECUÁRIA CONCOMITANTE AO ENSINO MÉDIO}

Os Institutos Federais de Educação, Ciência e Tecnologia, ou IFs, são Instituiçóes de natureza autárquica que possuem "autonomia administrativa, patrimonial, financeira, didático-pedagógica e disciplinar" (BRASIL, 2008), características estas que exigem dessas Instituiçóes a capacidade de construção e autogerenciamento de metas e açôes a serem desenvolvidas em seu âmbito 
educacional. O Art. 13, parágrafo III da Resoluçáo No 6 de 20 de setembro de 2012 que define as Diretrizes Curriculares Nacionais para a Educação Profissional Técnica de Nível Médio, dispóe que

Os conhecimentos e as habilidades nas áreas de linguagens e códigos, ciências humanas, matemática e ciências da natureza, vinculados à Educação Básica deverão permear o currículo dos cursos técnicos de nível médio, de acordo com as especificidades dos mesmos, como elementos essenciais para a formação e o desenvolvimento profissional do cidadão (BRASIL, 2012).

Nesse sentido, compatibilizamos com o entendimento de Veiga et. al (2013, p. 164) ao afirmar que este "preceito legal está sustentado na ideia de que a escola deve assumir, como uma de suas principais tarefas, o trabalho de refletir sobre sua intencionalidade educativa", inclusive, de acordo com essas proposiçôes, o PPC é um convite a esse importante exercício reflexivo, Veiga et. al (2013).

Os Institutos Federais, em seus diversos campi, como forma de atender a prerrogativa de sua autonomia didático-pedagógica, viabilizam a elaboração de seus Projetos Pedagógicos de Cursos - PPCs, que norteiam as práticas de ensinoaprendizagem desenvolvidas nessas Instituiçóes. Tal documento, segundo Veiga (2013) possibilita a reflexáo sobre a prática de ensino e as finalidades da escola, bem como o esclarecimento de sua função social e a reconfiguração das trajetórias a serem trilhadas, junto ao protagonismo dos demais sujeitos envolvidos no processo educativo.

A propósito do ensino médio, Veiga (2010) argumenta sobre a necessidade de superação do modelo educacional reprodutor de estruturas dominantes na sociedade, com vistas a promover valores que possibilitem a resistência e o confronto através da promoçáo de práticas inovadoras, principalmente a ruptura da fragmentação do trabalho, entre aqueles que o concebem e os que apenas executam.

Com isso, buscamos refletir sobre uma das propostas curriculares desencadeadas no contexto de ensino do Instituto Federal de Educação, Ciência e Tecnologia do Tocantins - IFTO, aqui representada pelo PPC de um Curso Técnico em Agropecuária Concomitante ao Ensino Médio (com vigência desde o ano de 2017), focalizando os objetivos da formação e o perfil de atuação do técnico de nível médio, conforme Quadro 1, bem como pela ementa do componente curricular "Redação de Documentos Técnicos e Oratória" em discussão no tópico dos resultados do trabalho. 
Quadro 1 - Objetivos da formação do técnico de nível médio em Agropecuária

\begin{tabular}{|c|c|}
\hline \multirow{2}{*}{ 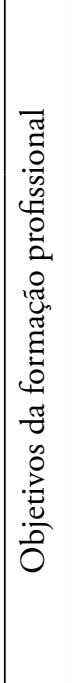 } & $\begin{array}{l}\text { Perfil de atuaçáo } \\
\text { Técnico de empresas rurais; empreendedor de planejamento, execução e condução de projetos } \\
\text { voltados para agricultura e zootecnia, Resolução de problemas em contextos profissionais "de } \\
\text { forma cidadã e em equipe" }\end{array}$ \\
\hline & $\begin{array}{l}\text { Objetivo geral: Formar profissionais técnicos de nível médio habilitados } \\
\text { Objetivos específicos: } \\
\text { Oportunizar educação permanente, requalificação do profissional em planejamento, } \\
\text { execução, acompanhamento, fiscalização, administração de etapas e projetos agropecuários } \\
\text { em propriedades rurais, elaboração de programas preventivos de sanitização na produçáo } \\
\text { animal e vegetal, realizaçáo de mediçáo, demarcação e levantamentos topográficos rurais; } \\
\text { por à disposição da sociedade profissionais conscientes de suas responsabilidades; integrar } \\
\text { ensino e trabalho com vistas a melhores condiçôes para a vida produtiva moderna, oferta de } \\
\text { formaçáo qualificada destinada a programas de assistência técnica, extensão rural e pesquisa; } \\
\text { projetar e aplicar inovaçóes nos processos de produçáo agropecuária, monitoramento e gestáo } \\
\text { de empreendimentos; profissionalização rápida para atividades específicas e delimitadas no } \\
\text { mundo do trabalho. }\end{array}$ \\
\hline
\end{tabular}

Fonte: Adaptado do PPC Técnico em Agropecuária (BRASIL, 2017)

Os objetivos da proposta curricular do curso em pauta dão destaque à formação profissional dos estudantes, tais como formação de profissionais dotados de saberes para atuar junto a "empresas, como empreendedores, colaboradores, administradores de propriedades rurais", com "habilidades" tanto no planejamento quanto na implementação, acompanhamento e fiscalização na implantação de ações mediadoras e inovadoras.

Todavia, para se alcançar o perfil profissional delineado, não basta apenas os saberes técnicos da profissão (CIAVATTA; RAMOS, 2011), posto que os imperativos da sociedade hodierna requerem, cada vez mais, o domínio das linguagens - os letramentos - do mundo das profissóes e das culturas contemporâneas (ROJO, 2013; GARCIA ET AL, 2016). Vivemos atualmente tempos de transformaçóes dos paradigmas dos modos de ensinar e aprender, o que suscita a premência de revisão e atualização dos componentes curriculares, já que estes representam o conjunto dos conhecimentos que a sociedade espera das instituiçóes educacionais. O próximo tópico dá conta da análise da ementa da disciplina Redação de documentos técnicos e oratória e de como tal documento é percebido e implementado no contexto pesquisado.

\section{PERCURSO METODOLÓGICO DO ESTUDO}

Para o desenvolvimento deste estudo, utilizamos o modelo de pesquisa qualitativa, posto que este tipo de abordagem permite compreender os fenômenos da realidade "centrando-se na compreensão e explicação da dinâmica das relaçôes sociais" (GERHARDT; SILVEIRA, 2009, p. 32), no que se refere a este trabalho, os fatos reais da atualidade envolvendo a educação profissional e as políticas 
públicas. Com objetivo de buscar maior familiaridade com o objeto de investigaçáo realizamos pesquisa exploratória de fontes teóricas da literatura especializada em estudos da linguagem e da educaçáo, análise de documentos oficiais e estudo de caso. Segundo Yin (2010), essa combinação de métodos de pesquisa possibilita maior compreensão e aprofundamento sobre o que se pretende investigar.

Para sua consecução, primeiramente revisou-se fontes teóricas sobre a temática. Mantivemos o diálogo dos aportes teóricos vygotskyanos concernentes aos processos de interação, mediação e internalização dos conhecimentos linguageiros com a Teoria da Transposiçáo didática de Yves Chevallard, bem como com a contribuição das obras de estudiosos do campo da educação profissional (RAMOS, 2010; MOURA, 2012) e dos letramentos (ROJO, 2013), entre outros.

Esses aportes teórico-conceptuais e metodológicos subsidiaram as escolhas feitas para o levantamento e os procedimentos de análise dos dados, fornecendo-nos insumos para as reflexôes e discussôes sobre o currículo do curso e sua organização (aqui representado pelo ementário da disciplina Redação de Documentos Técnicos e Oratória) e entrevista realizada com o professor acerca de sua implementação em tempos de ensino remoto, em um curso técnico de nível médio em Agropecuária de um Campus Avançado do IFTO.

No ementário, buscou-se analisar os conteúdos priorizados para o ensino da escrita e da oralidade; e, por meio de entrevista, as percepçóes (expectativas, inquietaçôes, limitaçóes) do professor responsável pelo ensino da disciplina acerca da organização curricular do curso e do processo de implementação desses saberes de linguagem na sala de aula considerando o atual cenário que estamos atravessando, de pandemia e consequente isolamento social.

O tratamento dos dados e os procedimentos analíticos estáo fundamentados no modelo de análise de conteúdo textual de Bardin (2011). No que se refere ao ementário, procedemos à leitura interpretativa de seu conteúdo conforme o Quadro 2. A entrevista realizada com o professor passou por transcrição e seus relatos organizados em categorias nos Quadros 3 e 4 constantes do tópico de discussão e resultados.

\section{DISCUSSÃO E RESULTADOS}

Com o propósito de responder aos objetivos do estudo, discutimos o resultado da análise de conteúdo do corpus textual que constitui o objeto de nosso estudo: (i) a ementa da disciplina Redação de documentos técnicos e oratória, documento representativo da organização curricular do Curso Técnico em Agropecuária Concomitante à etapa do Ensino Médio. Neste trabalho, destacamos os saberes/conteúdos de linguagem priorizados na política institucional; e, (ii) entrevista realizada com o professor da disciplina acerca de suas percepções sobre o processo ensino-aprendizagem dos saberes de linguagem na atual conjuntura socioeducacional. 
O Quadro 2 sintetiza os conteúdos priorizados no componente curricular em questão no curso técnico de nível médio em agropecuária correlacionando-os aos elementos que mais se aproximam das práticas de ensino da escrita e da oralidade.

Quadro 2 - Ementa da disciplina Redação de Documentos Técnicos e Oratória

Prática de elaboração de documentos técnicos; O método e produção de conhecimento; Prática de produção de respostas discursivas a questóes de interpretação de textos argumentativos; Estrutura e apresentação de seminários; Estratégias de leitura visando à compreensão e análise crítica; Prática de leitura e análise de textos argumentativos acadêmicos e náo-acadêmicos;

Temas transversais

Fonte: PPC Técnico em Agropecuária Concomitante ao Ensino Médio (BRASIL, 2017)

Conforme a Resolução CONSUP No/2017/CONSUP/IFTO a ementa da disciplina está formulada com 83,33 horas semestrais. Leitura, compreensão crítica e produçâo de textos escritos constituem as práticas de linguagem priorizadas na disciplina, tais como: "textos argumentativos acadêmicos e náo-acadêmicos" e "documentos técnicos". Os saberes da oratória não assumem destaque, em comparação à produção escrita sendo representada apenas pelo estudo da estrutura e apresentaçáo de seminários.

Tendo em vista o papel central da linguagem sobre as atividades e práticas sociais, conforme apontado em Vygotsky (1991, 2001) e Bakhtin (2011, 2014), comparando esses dados com os objetivos da formação profissional e o perfil de atuação descritos, anteriormente no Quadro 1, a base dos conteúdos constantes na ementa não atende a formaçáo integral do técnico de nível médio. Isso porque a emergência das novas linguagens trazidas pelas TDIC e as recentes exigências do mercado de trabalho demandam profissionais comunicativos que dominem diversas linguagens contemporâneas (GARCIA ET AL, 2016).

Decorrente dessas exigências sociais, os programas das disciplinas devem ser continuamente ajustados em sintonia com os propósitos da formação considerando as necessidades contextuais. Segundo Rojo (2013, p. 8-9), as profissóes da atualidade lidam com linguagens diversas. Contudo, a organizaçáo dos conteúdos disciplinares precisa estar voltada para "letrar" os "novos textos", saber escrever, ler, falar e compreender as linguagens emergentes (ROJO, 2013, p. 8-9). Assim, o ensino associado aos letramentos contemporâneos possibilita articular escola, vida pessoal e profissional. No entanto, dependem da mediaçáo do professor que poderá equalizar a utilizaçáo de ferramentas e instrumentos de ensino, fazendo uso de tecnologias de forma sistemática e intencional, isto é, em caráter pedagógico, com vista ao alcance dos objetivos de aprendizagem.

Para tratar das questóes que implicam a mediação do docente no processo ensino-aprendizagem, o Quadro 4 traz a fala da Professora da Disciplina (doravante PD) sobre a organização curricular do componente Redação de documentos técnicos e oratória, explicitando nas unidades enunciativas enumeradas sucessivamente de 1 a 11, suas percepçôes (perspectivas, inquietações e/ou limitaçôes) na consecução 
dos objetivos de aprendizagem durante os eventos de ensino remoto e anterior a ele, com base no desenvolvimento da ementa. Após apresentação do quadro, discutimos o resultado da análise de seu conteúdo.

Quadro 3 - Perspectivas, inquietaçôes e limitaçôes para o ensino de linguagem

\begin{tabular}{|c|c|}
\hline & Unidades enunciativas de análise \\
\hline 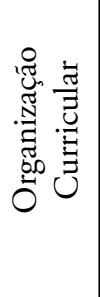 & $\begin{array}{l}\text { (1) a ementa é suficiente e possibilita trabalho abrangente, flexível nas práticas de ensino e } \\
\text { permite fazer adaptaçóes; } \\
\text { (2) a disciplina permite formação de cidadãos empreendedores, motiva os estudantes a } \\
\text { se posicionarem e comunicarem criticamente, transformar suas realidades, seus projetos } \\
\text { profissionais de forma consciente; } \\
\text { (3) no ensino presencial ou remoto a utilização dos computadores nos laboratórios de } \\
\text { informática do campus é uma forma de promover o letramento digital dos alunos; }\end{array}$ \\
\hline 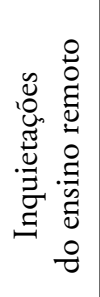 & $\begin{array}{l}\text { (4) como implementar, avaliar e mensurar conquistas de aprendizagem; } \\
\text { (5) para adaptar os conteúdos da ementa, a carga horária é insuficiente; } \\
\text { (6) qual o tipo de material didático mais adequado às aspiraçóes dos estudantes e que } \\
\text { desperte o interesse deles; } \\
\text { (7) como relacionar saberes de linguagem com a formação profissional; } \\
\text { (8) o problema náo está na modalidade de ensino a distância ou presencial, mas na } \\
\text { compreensão dos alunos sobre o sentido do conteúdo ensinado. }\end{array}$ \\
\hline 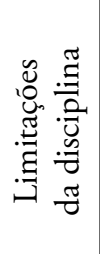 & $\begin{array}{l}\text { (9) a carga horária da disciplina não possibilita trabalhar completamente os conteúdos e as } \\
\text { habilidades previstos no ementário; } \\
\text { (10) para a escrita, a carga horária permite o ensino de interpretação, produção, coesão, } \\
\text { coerência; } \\
\text { (11) para o ensino da oralidade, ou seja, a oratória, trabalha-se a noção de apresentação de } \\
\text { seminários. }\end{array}$ \\
\hline
\end{tabular}

Fonte: Elaboração própria

Conforme revelado, nas unidades 1, 2 e 3 do Quadro 4, a PD tem expectativa otimista com relação à organização curricular que envolve o componente em questão. Em seu discurso, tanto a "ementa" quanto a "disciplina" se alinham à formação de "cidadáos empreendedores críticos e comunicativos", se ajustando ao ensino remoto com auxílio dos dispositivos digitais no trabalho de letramento do aluno. No entanto, segundo Sacristán (2000) o currículo prescreve os rumos do ensino, mas sua concretização depende dos imperativos contextuais, sócio-históricos e culturais, dentre esses a base do conhecimento didático-pedagógico do professor em saber adequar seu projeto de ensino.

Os enunciados 4, 5, 6, 7 e 8 confirmam essa assertiva nos apontando que o atual contexto de pandemia da Covid-19 e do consequente isolamento social, o ensino da disciplina Redação de documentos técnicos e oratória está marcado por um contexto de inquietaçóes devido às redefiniçóes e adaptaçóes do modelo de ensino presencial para o ensino remoto. 
Decorrente disso, adequaçóes devem ser feitas nos modos e procedimentos de ensinar os conteúdos previstos na organizaçáo curricular. Na voz do $\mathrm{PD}$, isso ocorre, principalmente, com relação aos procedimentos avaliativos do avanço de aprendizagem dos alunos, à "adaptação" dos saberes previstos no ementário, o tempo insuficiente das aulas e de materiais didáticos que despertem "o interesse" do público discente. Além disso, há inquietaçôes quanto à adequação dos conteúdos linguageiros aos propósitos da formação. Diante desse desafio, a PD argumenta que "o problema" enfrentado não é de ordem do "ensino a distância ou presencial", mas está relacionado à capacidade cognitiva de assimilação dos saberes de linguagem pelos alunos.

Em face desse quadro complexo de adaptaçóes do processo ensinoaprendizagem no qual a PD está inserida, os contributos de Chevallard (2013) trazem elucidações bastante pertinentes. Para o autor a transposição/adaptação dos saberes de qualquer disciplina em situaçóes de ensino, requer o entendimento da vida didática considerando a preeminência da relação de três elementos centrais que tornam as aprendizagens significativas: a função do professor, do aluno e do saber, conforme já apresentamos anteriormente. Nesse ponto de vista, para que a aprendizagem se concretize e os objetivos do ensino sejam alcançados, os saberes devem ser organizados de forma que façam sentidos para ambas as partes.

Identificamos, ainda, no discurso do $\mathrm{PD}$, inquietações que resultam em limitaçóes para o alcance dos objetivos de ensino e de aprendizagem. Tais constataçôes estão representadas nas unidades 9,10 e 11 as quais indicam que a carga horária dispensada à disciplina impossibilita implementar os conteúdos necessários ao desenvolvimento de habilidades dos alunos concernentes à escrita e à oralidade.

Em uma visão global das unidades enunciativas do Quadro 3, compreendemos que problemas (inquietaçôes e limitaçôes) que afetam as expectativas do PD estão mais relacionados à necessidade, segundo Veiga (2013, p.164), de a instituição colocar a organização curricular como exercício de reflexão sobre a "intencionalidade educativa" em sintonia com os acontecimentos que implicam a formação ofertada. Logo, em tempos de (re)aprendizagem dos conhecimentos, é preciso buscar a compreensão da realidade que se impóe como uma verdadeira "leitura de mundo" (FREIRE, 1989). E dessa leitura, trazer para a centralidade da educação profissional, açôes de multi/letramentos (ROJO, 2013) articulando as linguagens emergentes do atual contexto, conforme a expectativa do PD representada na unidade 3 , como possibilidade de integração entre ensino presencial e ensino remoto, bem como dos saberes do passado com os do presente. A seguir discutimos as questóes de implementação do processo ensino-aprendizagem nesse âmbito.

O Quadro 4 delimita as unidades enunciativas categorizadas em "desafios no ensino" e "problemas de aprendizagem", enumeradas sucessivamente de 1 a 15 colocando em destaque as configuraçôes do trabalho didático do PD na disciplina de Redação de documentos técnicos e oratória com seus alunos desde o início do isolamento social. 
Quadro 4-Dos desafios do ensino de linguagem aos problemas de aprendizagem

\begin{tabular}{|c|c|c|}
\hline \multirow{2}{*}{ 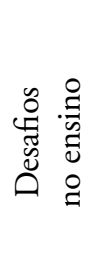 } & 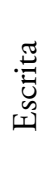 & $\begin{array}{l}\text { (1) falta de conceitos básicos do Português pelos alunos; } \\
\text { (2) o uso do Whats } A p p \text { interfere na elaboração escrita formal dos alunos; } \\
\text { (3) ensinar uso de resumos, sínteses, etc., de forma linear; } \\
\text { (4) muitos desafios de compreensão dos sentidos do texto pelos alunos; }\end{array}$ \\
\hline & 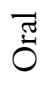 & $\begin{array}{l}\text { (5) trabalho centralizado na prática da apresentação de seminários; } \\
\text { (6) tentativas de articulaçáo e debates com exposiçáo de ideias; }\end{array}$ \\
\hline \multirow{2}{*}{ 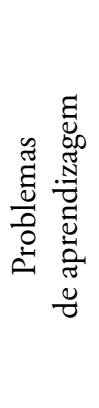 } & 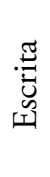 & $\begin{array}{l}\text { (7) os alunos têm muita resistência ao escrever; } \\
\text { (8) defasagem nas práticas da escrita; } \\
\text { (9) problemas de ortografia; } \\
\text { (10) falta de concentração nas atividades de ensino remoto; }\end{array}$ \\
\hline & 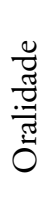 & $\begin{array}{l}\text { (11) resistência dos estudantes à apresentação de seminários, timidez; } \\
\text { (12) receiam cometer "possíveis" erros diante dos colegas e professor; } \\
\text { (13) ficam apreensivos por estarem sendo avaliados; } \\
\text { (14) falta domínio e decoram o conteúdo; } \\
\text { (15) excessiva leitura durante as apresentaçôes orais. }\end{array}$ \\
\hline
\end{tabular}

Fonte: Elaboração própria

As palavras do PD, representadas nos segmentos 1, 2, 3 e 4, nos revelam que suas atividades didático-pedagógicas no ensino da escrita estão permeadas de desafios concernentes à falta de saberes básicos do português formal por parte dos discentes e do excessivo uso das redes sociais, mais especificamente, do "WhatsApp". $\mathrm{O}$ que consequentemente, em sua perspectiva, tem afetado a produção da escrita formal daqueles sujeitos e o ensino de gêneros "resumos e síntese" linearmente, além de dificuldades de compreensão dos textos produzidos por eles.

Acerca do fato de que as redes sociais impactam o ensino de linguagem, os aportes gramscianos de educação humana nos advertem que o papel da escola, dentre outras funçóes, é o de acolher as diversidades e culturas encontradas nos alunos. Isso porque o descompasso, entre os saberes da vida e os saberes da escola é o que gera a crise no ensino; e que, notadamente, retomará o equilíbrio quando considerar "a participação realmente ativa do aluno na escola, que só pode existir se a escola for ligada à vida" (GRAMSCI, 2001, p. 45). A integração entre tais saberes se soma tal como preconizado na obra de Freire (1989) e Vygotsky (2001). No entanto, é preciso ainda considerar, segundo Bakhtin (2014), que a linguagem é, por si mesma, definida por sua diversidade cultural.

Quanto ao ensino da oralidade, devido às limitaçôes da carga horária da disciplina (conforme unidade 11, Quadro 3), o trabalho didático-pedagógico do PD prioriza apenas "seminários" e os "debates" segundo indica sua fala nos enunciados 5 e 6 . O que revela distanciamento do que está previsto nos objetivos da formação profissional no Quadro 1 com o conteúdo efetivamente possível a ser ensinado, o que segundo Chevallard (1991, p. 16), a instituição precisa proceder "o exercício da vigilância epistemológica", ou seja, se empenhar para que os ensinos 
dos saberes sejam contextualizados evitando sua fragmentação e descontextualização dos propósitos da formação do aluno.

$\mathrm{Na}$ categoria dos problemas de aprendizagem, as unidades 7, 8, 9 e 10 póese em evidencia que o público discente enfrenta dificuldades de apropriação dos construtos necessários à produção escrita formal, tanto no formato de ensino presencial como remoto. Esses dados apontam para a necessidade de se rever o modo de exposição do aluno aos modelos de gêneros textuais requisitados pela esfera profissional, na qual os técnicos de nível médio atuarão, que, segundo Bakhtin (2011), são modelos para agir socialmente servindo igualmente de fomento para a produçáo discursiva de outros textos. $\mathrm{O}$ que por sua vez pode auxiliar o aluno na superação de sua resistência no momento da produção dos discursos de sua língua materna.

Tal resistência é também ratificada nos segmentos de 11 a 15 na categoria dos problemas implicando a produção do discurso oral. Assim, os termos "a timidez", os "possíveis erros", "ficam apreensivos", "decoram o conteúdo" para as "apresentaçôes orais" demarcam os impasses que cerceiam a motivação da aprendizagem do grupo estudantil. $\mathrm{O}$ ensino da oratória se pauta na prática do letramento vernacular valorizando-se os modos de escrever e de falar em conformidade com as normas formais de uso da linguagem centradas no exercício da profissão.

Segundo Gramsci (2009), Ramos (2010) e Moura (2012) é preciso articular nos eixos estruturantes do currículo os saberes necessários à vida e às profissóes com vistas a uma formação do técnico de nível médio preparando-o para os desafios da imprevisibilidade dos fatos sociopolíticos e culturais, bem como das demandas do mundo do trabalho. Nesse cenário, urge a apropriaçáo da linguagem e sua integração/atualização curricular.

\section{CONSIDERAÇÓES FINAIS}

Os aportes teórico-metodológicos e os procedimentos analíticos mobilizados nos possibilitaram alcançar os objetivos do presente estudo. Discutimos e refletimos sobre a organização curricular do Curso Técnico em Agropecuária Concomitante à etapa do Ensino Médio de um Campus do IFTO, conforme consideraçōes feitas, tendo por base os Quadro 1, Quadro 2 e Quadro 3. Investigamos as percepçóes do PD sobre o complexo processo de ensino-aprendizagem dos saberes de linguagem priorizados na ementa da disciplina Redação de documentos técnicos e oratória. Oportunizamos voz a esse profissional do ensino sobre sua prática na atual conjuntura de pandemia e isolamento social, a partir da análise de conteúdo de seus relatos contidos no Quadro 3 e no Quadro 4.

$\mathrm{O}$ trabalho possibilitou a compreensão de que o ensino da linguagem em tempos de ensino remoto requer um redimensionamento do currículo, atualização dos conteúdos de acordo com o contexto sociopolítico, cultural e educacional vigente. Além disso, os dados analisados suscitam a premência de apoio institucional e preparação do professor e dos alunos. 
Consoante à análise construída acerca dos estudos aqui apresentados, tais resultados nos apontam para a necessidade, sobretudo, dentro do contexto de Educaçáo Profissional e Tecnológica, de um modelo de ensino que considere as novas competências comunicativas, inclusive, as presentes nas atuais formas de utilização da linguagem comunicativa dos sujeitos.

Com relação à análise feita sobre o componente curricular de Língua portuguesa, aqui representado pela disciplina de Redaçáo de documentos técnicos e oratória e das percepçôes do PD, nota-se uma sobreposição dos conteúdos para o ensino da língua escrita e de suas normas gramaticais (conforme quadro 3 , unidade enunciativa 10 e quadro 4, unidade enunciativa 9) e, consequentemente, a utilização de materiais e instrumentos impressos em detrimento de práticas associadas ao desenvolvimento de competências comunicativas orais e de meios digitais.

Há, portanto, que se considerar um modelo de ensino que também privilegie práticas de multiletramentos, tendo como exímio cenário o contexto escolar, em qualquer um de seus níveis de ensino, já que este exercício corrobora para a prática das linguagens contemporâneas, inclusive para o mundo do trabalho, envolvendo tanto o uso de gêneros textuais escritos como orais nos eventos de comunicaçáo.

A BNCC, por sua vez, também, trata dessa questão e possui em seu bojo algumas orientaçôes destinadas ao ensino de linguagem, no ensino médio, quando demonstra indícios que se direcionam na proposição de ações para a prática dos multiletramentos como premissa para o ensino de competências e habilidades comunicativas presentes na contemporaneidade, embora a ênfase normativa dada pela BNCC esteja, substancialmente, na aprendizagem de competências e habilidades pelos estudantes.

A proeminência do ensino para o Trabalho, tão considerada dentro das propostas curriculares da EPT, sob a ótica aqui discutida, deve ser considerada como de princípio educativo (BRASIL, 2018; CIAVATTA, 2008; KUENZER, 1989), por promover um ensino que supere o excessivo academicismo e/ou conteudismo que muito se limita a uma formação unicamente profissionalizante e de escolhas estreitas ofertadas aos estudantes deste contexto escolar.

Ademais, nesse artigo, consideramos que os Instituto federais são Instituições de grande potencial e que, com base neste estudo, no que se refere à oferta do ensino desenvolvido em cursos técnicos/profissionalizantes, não deve limitar-se apenas ao ensino dos conteúdos e à aprendizagem de determinadas destrezas para o exercício de um ofício técnico, por exemplo, mas suscitar uma formação que, conjuntamente, privilegie a atuaçáo consciente e reflexiva de seus estudantes frente às diferentes situaçóes do mundo do mercado de trabalho e da própria vida.

Caso contrário, nós estaremos contribuindo para a formação de sujeitos que apenas sabem apertar parafusos, mas não são dirigentes reflexivos de suas açôes, levando-se em consideração o alto nível de complexidade que nos é apresentado pelo modo de produção capitalista a que os estudantes também estão sujeitos. Principalmente em tempos de pandemia, que requer novas aprendizagens para professores, alunos e sociedade. 


\section{REFERÊNCIAS}

BARDIN, Laurence. Análise de conteúdo. São Paulo: Edições 70, 2011.

BAKHTIN, Mikhail Mikhailovich. Estética da Criação Verbal. Tradução: Paulo Bezerra. São Paulo: Martins Fontes, 2011.

BRASIL. MEC. Base Nacional Comum Curricular. Brasília: 2018. Disponível em: http://basenacionalcomum.mec.gov.br/images/BNCC20dezsite.pdf. Acesso em: 20 de abr. 2020.

BRASIL. MEC. Constituição da República Federativa do Brasil Brasília: 1988.

Disponível em: http://www.planalto.gov.br/ccivil_03/constituicao/constituicao.htm. Acesso em: 20 de ago. 2020.

BRASIL. MEC. Diretrizes Curriculares Nacionais para a Educação Profissional Técnica de Nível Médio. Resolução CNE/CEB 6/2012. Diário Oficial da União, Brasília, 21 de setembro de 2012, Seção 1, p. 22. Disponível em: <http://portal.mec.gov.br/index. php?option=com_docman\&view=download \&alias=11663-rceb006-12-pdf\&category_ slug=setembro-2012-pdf\&Itemid=30192>. Acesso em: 27 de ago. 2020.

BRASIL. Ministério da Educação. Institui a Rede Federal de Educação Profissional, Científica e Tecnológica, cria os Institutos Federais de Educação, Ciência e Tecnologia Brasília: MEC, 2008. Disponível em: http://www.planalto.gov.br/ccivil_03/_Ato20072010/2008/Lei/L11892.htm. Acesso em: 20 de ago. 2020.

BRASIL. MEC. Lei de Diretrizes e Bases da Educação Nacional no Brasil. Brasília: 1996. Disponível em: http://www.planalto.gov.br/ccivil_03/leis/19394.htm. Acesso em: 20 de ago. 2020.

BRASIL. MEC. Lei de Reforma do Ensino Médio. Brasília: MEC, 2017. Disponível em: http://www.planalto.gov.br/ccivil_03/_ato2015-2018/2017/lei/113415.htm. Acesso em: 20 de ago. 2020.

BRASIL. Ministério da Saúde. O que é a COVID-19?. Disponível em: <https:// coronavirus.saude.gov.br/sobre-a-doenca>. Acesso em: 27 de ago. 2020.

BRASIL. Projeto-Pedagógico de Curso: técnico em agropecuária/concomitante ao Ensino Médio. Resolução CONSUP No/2017/CONSUP/IFTO. Disponível em: Sistema Eletrônico de Informação (SEI/IFTO), processo no. 23235.015970/2017-16. Acesso em: 10 jul. 2020.

CIAVATTA, M; RAMOS, M. Ensino Médio e Educação Profissional no Brasil: Dualidade e fragmentação. Revista Retratos da Escola, Brasília, v. 5, n. 8, p. 27-41, jan./jun. 2011. Disponível em: <http//www.esforce.org.br>. Acesso em: 27 de ago. 2020.

CIAVATTA, M. A FORMAÇÃO INTEGRADA: a escola e o trabalho como lugares de memória e de identidade. Trabalho necessário, Ano 3, nº. 3, 2008. ISSN: 1808-799X 
CHEVALLARD, Yves. La Transposition Didactique: du savoir savant au savoir enseigné. Grenoble: La Pensée Sauvage Editions, 1991.

CHEVALLARD, Yves. Sobre a teoria da transposição didática: algumas considerações introdutórias. Trad. Cleonice Puggian. Revista de Educação, Ciências e Matemática, v.3, n.2, mai./ago. 2013. ISSN 2238-2380. Disponível em: <http://publicacoes.unigranrio. edu.br/index.php/recm/article/view/2338 > Acesso em: 20 de Abr. 2020.

FREIRE, P. A importância do ato de ler: em três artigos que se completam. Paulo Freire. - São Paulo: Autores Associados: Cortez, 1989. (Coleção polêmicas do nosso tempo; 4).

FERREIRA, A; NUNES, M. da G.Brasil. O Currículo da Educação Profissional da Legislação Brasileira. In: CONGRESSO NACIONAL DE EDUCAÇÃO, EDUCERE, XI, 2013, Curitiba, Pontifícia Universidade Católica do Paraná., de 23 a 26 de set.2013.

GAGLIARDI, E. ROJO, R.; MOURA, E. (orgs.). Multiletramentos na escola. Sáo Paulo: Parábola Editorial, 2012. 264p. Cadernos Cenpec, São Paulo, v.2, n.1, p.241244, julho 2012.

GARCIA, Clarisse de P. et al. Multiletramentos no ensino público: desafios e possibilidades. Revista Práticas de Linguagem, Juiz de Fora, v. 6 especial - Escrita discente - 2016. Disponível em: <https://www.uff.br/praticasdelinguagem/>. Acesso em: 10 de ago. 2020.

GERHARDT, Tatiana E.; SILVEIRA, Denise T. Métodos de Pesquisa. Coordenado pela Universidade Aberta do Brasil - UAB/UFRGS e pelo Curso de Graduação Tecnológica Planejamento e Gestão para o Desenvolvimento Rural da SEAD/UFRGS. Porto Alegre: Editora da UFRGS, 2009.

GRAMSCI, A. Cadernos do Cárcere. Edição e tradução, Carlos Nelson Coutinho; co-edição, Luiz Sérgio Henriques e Marco Aurélio Nogueira, 2o edição, Rio de Janeiro: Civilização Brasileira, 2001.

KUENZER, Acácia Z. O trabalho como princípio educativo. Cad., Pesq., São Paulo (68): 21-28, fevereiro, 1989.

MARCUSCHI, Luiz. Fala e escrita. Luiz Antônio Marcuschi e Ângela Paiva Dionísio (orgs). $1^{\circ}$ Ed., $1^{\circ}$ reimp. - Belo Horizonte: Autêntica, 2007. 208 p. ISBN 85-7526-158-4. . Marxismo e Filosofia da Linguagem. São Paulo: Hucitec, 2014.

MOURA, Dante H; FILHO, Domingos Lima L.; SILVA, Mônica R. POLITECNIA E FORMAÇÃO INTEGRADA: confronto conceituais, projetos políticos e contradiçóes históricas da educação brasileira. Revista Brasileira de Educação, v. 20, n. 63, p. 10571080, out.-dez., 2015.

MOREIRA, Marco A. Teorias de Aprendizagem. São Paulo: EPU, 1999. 
ROSA, Cleci T. W. da; LOCATELLI, Aline. Produtos educacionais: diálogo entre universidade e escola. Ensino de Ciências e Tecnologia em Revista, v. 8, n. 2, p. $26-$ 39, jul.-ago., 2018. Disponível em: <http://srvapp2s.santoangelo.uri.br/seer/index.php/ encitec/article/view/2716/pdf-rosa> . Acesso em: 27 de ago. 2020.

ROJO, Roxane. O letramento escolar e os textos da divulgaçáo científica - a apropriaçáo dos gêneros de discurso na escola. Linguagem em Dis(curso) - LemD, v. 8, n. 3, p. 581-612, set./dez. 2008.

ROJO, R. MULTILETRAMENTOS. EDUCAÇÃO NO SÉCULO XXI, São Paulo: Fundação Telefônica, (Entrevista), p. 8, 2013. Disponível em: <http:// fundacaotelefonicavivo.org.br/wp-content/uploads/2013/03/caderno3_multiletramentos. pdf>. Acesso em: 27 de ago. 2020.

SACRISTÁN, J. Gimeno. O currículo: uma reflexão sobre a prática. Trad.: Ernani F. da F. Rosa - $3^{a}$ ed. - Porto Alegre: Artmed, 2000.

VEIGA, Ilma P. A. Projeto político-pedagógico da escola de ensino médio e suas articulaçóes com as açóes da secretaria de educaçáo. ANAIS DO I SEMINÁRIO NACIONAL CURRÍCULO: EM MOVIMENTO - Perspectivas atuais, Belo Horizonte, novembro de 2010.

VEIGA, Ilma P. A. Projeto Político-Pedagógico da Escola: uma construçáo possível. Campinas: Papirus Editora, 2013.

VYGOTSKI, Lev S. A formaçáo social da mente. São Paulo: Martins Fontes, 1991.

VYGOTSKY, Lev S. A construçáo do pensamento e da linguagem. Tradução do russo de Paulo Bezerra. São Paulo: Martins Fontes, 2001.

YIN, Robert. K. Estudo de caso: planejamento e métodos. 4. ed. Porto Alegre: Bookman, 2010. 